\title{
Inertial Effects in Two-Phase Flow through Fractures
}

\author{
M. Fourar ${ }^{1}$ and R. Lenormand ${ }^{2}$ \\ 1 École des mines de N ancy, LEM TA, Parc de Saurupt, $54042 \mathrm{~N}$ ancy Cedex - France \\ 2 Institut français du pétrole, 1 et 4 avenue de Bois-Préau, 92852 Rueil-M almaison Cedex - France \\ e-mail: fourar@mines.u-nancy.fr - roland.lenormand@ifp.fr
}

\begin{abstract}
Résumé - Effets inertiels dans les écoulements diphasiques en fractures - Différents modèles de description des écoulements diphasiques dans une fracture sont présentés : modèles du coefficient d'inertie, de «passabilité » et de Lockhart-Martinelli. Ces modèles sont ensuite utilisés pour interpréter des résultats expérimentaux obtenus avec un écoulement d'eau et d'air dans une fracture rugueuse. Il apparaît que les coefficients de perméabilités relatives classiques $K r$ (sans terme d'inertie) ne dépendent pas uniquement de la saturation mais également du rapport des débits des deux fluides. L'existence d'une famille de courbes des $\mathrm{Kr}$ en fonction de la saturation à débit élevé peut être considérée comme un critère de la manifestation des effets inertiels. En tenant compte des effets inertiels, les modèles du coefficient d'inertie et de passabilité permettent de décrire correctement les résultats expérimentaux. Cependant, ces modèles font intervenir quatre paramètres dont la détermination nécessite d'autres investigations. En revanche, le modèle de Lockhart-Martinelli ne comporte que deux paramètres et peut être utilisé pour prédire les résultats expérimentaux. Une relation empirique utilisée en génie chimique pour les milieux poreux permet de prédire les résultats expérimentaux avec un écart relatif moyen inférieur à $20 \%$, sans ajustement supplémentaire. Pour les trois modèles, l'utilisation du rapport des débits des fluides, plutôt que la saturation, donne de meilleurs résultats.

Mots-clés : écoulement diphasique, perméabilités relatives, effets inertiels, Forchheimer, coefficient d'inertie, passabilité, milieu poreux, fracture.
\end{abstract} Abstract - Inertial Effects in Two-Phase Flow through Fractures - Different approaches for
modeling inertial effects during single-phase and two-phase flows through a fracture are presented:
inertial factor, passability and Lockhart-Martinelli models. These different approaches are then used to
interpret experiments for air/water flow through a rough fracture. For these two-phase flow experiments,
the standard relative permeabilities (no inertial terms) are not only functions of the saturation but also of
the flow rate ratio. This family of curves at high velocity can be seen as a criterion for the presence of
inertial effects. By taking account of inertial effects, the inertial factor and passability models are similar
and provide a good representation of the experimental data. However, four unknown parameters must be
determined and the models cannot be used for prediction without further research. The Lockhart-
Martinelli approach has only two parameters to fit and can be used for prediction. An empirical law used
for porous media in chemical engineering agrees within $20 \%$ with air/water experiments without any
additional adjustment of parameters. For the three approaches, the use of the ratio of the flow rates as
variable instead of the saturation gives better results.
Keywords: two-phaseflow, relative permeabilities, inertial effects, Forchheimer, inertial factor, passability, porous media, fracture. 


\section{IN TRO DUCTIO N}

Multiphase flow of various fluids through fractured rocks is involved in several industrial activities such as oil and gas recovery, geothermal energy and storage of radioactive wastes. In many cases, the fluids flow in very few open fractures or porous layers with very high permeability and, therefore, flow rates are high enough to generate inertial effects. High flow rates of gas and liquids can also be found in chemical engineering (trickle beds) and in problems related to the cooling of debris after an accident in a nuclear plant. The purpose of this paper is to review and discuss the different approaches used to account for inertial flow during multiphase flow through porous media and fractures.

The different approaches for modeling inertial effects during the flow of a single-phase are first described. Then, a generalization of these different models for two-phase flow is proposed and the relationships between the models are discussed. Finally, the various models are used to interpret a set of experiments for air/water flow through a single rough fracture.

\section{SIN G LE-PHASE FLO W}

Single-phase flow in porous media is generally modeled using Darcy's law (Darcy, 1856) which is assumed to be valid as long as the inertial forces are negligible compared to viscous forces (Lindquist, 1933; Schneebeli, 1955; Hubbert, 1956; Scheidegger, 1960; Chauveteau and Thirriot, 1967). The same approach is also used for flow in fractures. For a horizontal flow with no gravity effect, this law is written in the form:

$$
-\frac{\mathrm{d} P}{\mathrm{~d} x}=\frac{\mu V}{K}
$$

where $\mathrm{d} P / \mathrm{d} x$ is the pressure gradient, $\mu$ is the dynamic viscosity, $K$ is the permeability, and $V$ is the superficial velocity (flow rate per unit of section area). When inertial forces cannot be neglected, the pressure gradient is approximated by a quadratic function of the superficial velocity. There are several empirical relationships that take inertial effects into account (Bear, 1972; Dullien, 1992). In petroleum engineering, the most commonly used is the Forchheimer's equation which includes an additional term $\beta \mu V^{2}$ to account for inertial effects (Forchheimer, 1914):

$$
-\frac{\mathrm{d} P}{\mathrm{~d} x}=\frac{\mu V}{K}+\beta \rho V^{2}
$$

where $\rho$ is the fluid density and $\beta$ is called the inertial factor or the non-Darcy flow coefficient. In the nuclear industry, a similar relationship uses the notion of passability factor $\eta$ (Buchlin and Stubos, 1987):

$$
-\frac{\mathrm{d} P}{\mathrm{~d} x}=\frac{\mu V}{K}+\frac{\rho V^{2}}{\eta}
$$

In chemical engineering, the pressure drop with inertial effects is generally related to the porosity $\varepsilon$ of the medium and to the average pore diameter $d$ through the Ergun's equation (Ergun, 1952):

$$
-\frac{\mathrm{d} P}{\mathrm{~d} x}=A \frac{(1-\varepsilon)^{2}}{\varepsilon^{3} d^{2}} \mu V+B \frac{(1-\varepsilon)}{\varepsilon^{3} d} \rho V^{2}
$$

where $A$ and $B$ are both constants. The first term, which is used to estimate the permeability, is also known as the Kozeny-Carman's equation in the petroleum literature (Dullien, 1992):

$$
K=\frac{\varepsilon^{3} d^{2}}{A(1-\varepsilon)^{2}}
$$

Comparison of the inertial term in the three equations leads to the following relationship:

$$
\beta=\frac{1}{\eta}=B \frac{(1-\varepsilon)}{\varepsilon^{3} d}
$$

Several studies were devoted to predicting the parameters used in the previous relationships. In most of the studies (Cornell and Katz, 1953; Bird, Stewart and Lightfoot, 1960; Geertsma, 1974; Neasham, 1977; Noman and Archer, 1987), the inertial factor $\beta$ is essentially a function of geometrical features of the medium (porosity, permeability, and roughness). However, Tiss and Evans (1989) showed that $\beta$ is also a function of the fluid properties. Ergun (1952) proposed $A=180$ and $B=1.8$ as universal values. But other values of $A$ and $B$ are also presented in the literature (Bear, 1972). These various results show that the parameters related to viscous and inertial effects cannot be predicted accurately. They must be determined experimentally.

For flow in a fracture, the same approaches can be used. However, the Ergun's equation is not useful since it is difficult to define an equivalent porosity for the fracture.

\section{TW O-PHASE FLOW}

Modeling two-phase flow in porous media and fractures is based on the generalization of the single-phase flow equations. The first two approaches, inertial factor and passability, split the viscous and inertial effects. For both models, the viscous effect is modeled using the concept of relative permeability. A third approach, developed by Lockhart and Martinelli (1949), considers globally viscous and inertial effects.

We first remind of the notion of relative permeability, which is a generalization of Darcy's equation (1) when inertial forces are negligible compared to viscous forces:

$$
\begin{gathered}
-\frac{\mathrm{d} P_{L}}{\mathrm{~d} x}=\frac{\mu_{L} V_{L}}{K r_{L} K} \\
-\frac{\mathrm{d} P_{G}}{\mathrm{~d} x}=\frac{\mu_{G} V_{G}}{K r_{G} K}
\end{gathered}
$$


where subscripts $L$ and $G$ stand for liquid and gas, and $K r$ is the relative permeability. Note that when capillary forces are negligible, the pressure gradients in the two fluids are equal. Consequently, $\mathrm{d} P_{L} / \mathrm{d} x=\mathrm{d} P_{G} / \mathrm{d} x=\mathrm{d} P / \mathrm{d} x$ and $K r_{L}$ and $K r_{G}$ are related to the superficial velocity ratio by:

$$
\frac{K r_{L}}{K r_{G}}=\frac{\mu_{L} V_{L}}{\mu_{G} V_{G}}=X
$$

Marle (1981) has established that the relative permeabilities are functions of several dimensionless groups involving properties of both the fluid and the medium. But, at least in porous media, it is generally assumed that the $K r$ depends essentially on the phase saturation. Several studies were devoted to establishing relationships between relative permeabilities and the saturation. The most commonly used relationships for $\mathrm{Kr}$ in porous media are power laws (Corey, 1954):

$$
\begin{gathered}
K r_{L}=S_{e}^{4} \\
K r_{G}=\left(1-S_{e}\right)^{2}\left(1-S_{e}^{2}\right)
\end{gathered}
$$

In these relations, $S_{e}$ is the effective liquid-phase saturation defined by:

$$
S_{e}=\frac{S_{L}-S_{r}}{1-S_{r}}
$$

where $S_{L}$ is the liquid-phase saturation and $S_{r}$ the residual saturation. In fact, the value of the exponent in Equations (10) and (11) has been found to vary for different porous media (Brooks and Corey, 1966).

\subsection{The Inertial Factor Model}

The inertial factor approach is based on the generalization of Forchheimer's equation (2) for the two fluids. It was developed for petroleum engineering to describe two-phase flow occurring in the near-wellbore region of high-capacity gas reservoirs and it is also used for condensate reservoirs:

$$
\begin{aligned}
& -\frac{\mathrm{d} P_{L}}{\mathrm{~d} x}=\frac{\mu_{L} V_{L}}{K r_{L} K}+\beta_{L} \rho_{L} V_{L}^{2} \\
& -\frac{\mathrm{d} P_{G}}{\mathrm{~d} x}=\frac{\mu_{G} V_{G}}{K r_{G} K}+\beta_{G} \rho_{G} V_{G}^{2}
\end{aligned}
$$

The above equations contain four unknown coefficients, which are functions of saturation or velocities of the fluids: the relative permeabilities $K r_{L}$ and $K r_{G}$ and the inertial factors $\beta_{L}$ and $\beta_{G}$. Few experimental studies were performed in order to quantify $\beta_{L}$ and $\beta_{G}$ for fluids flowing simultaneously (Martins, Milton-Taylor and Leung, 1990; Ali, McGauley and Wilson, 1997; Blom and Hagoort, 1998). So far, there is no correlation proposed in the literature. Other studies (Geertsma, 1974; Evans and Evans, 1986; Evans,
Hudson and Greenlee, 1987; Martins, Milton-Taylor and Leung, 1990; Narayanaswamy, Sharma and Pope, 1998) attempted to find $\beta_{G}$ when the gas is flowing while the liquid remains immobile. The main correlation proposed in this case is the correlation of Geertsma (1974), where $S$ is saturation and $\varepsilon$ is porosity:

$$
\beta_{G}=\frac{0.005}{K^{0.5} \varepsilon^{5.5}} \frac{1}{\left(K r_{G}\right)^{0.5}\left(1-S_{L}\right)^{5.5}}
$$

\subsection{The Relative Passability Model}

The relative passability approach is based on the generalization of the passability (Eq. 3). It was developed for nuclear engineering in connection with the prevention of accidents in nuclear reactors (Buchlin and Stubos, 1987):

$$
\begin{array}{r}
-\frac{\mathrm{d} P_{L}}{\mathrm{~d} x}=\frac{\mu_{L} V_{L}}{K r_{L} K}+\frac{\rho_{L} V_{L}^{2}}{\eta r_{L} \eta} \\
-\frac{\mathrm{d} P_{G}}{\mathrm{~d} x}=\frac{\mu_{G} V_{G}}{K r_{G} K}+\frac{\rho_{G} V_{G}^{2}}{\eta r_{G} \eta}
\end{array}
$$

where $K r$ and $\eta r$ stand for the relative permeability and passability, respectively.

As for the $\beta$ approach, there are four unknown coefficients: $K r_{L}, K r_{G}, \eta r_{L}$, and $\eta r_{G}$. Some authors suggest that the relative permeability and passability of each fluid must be equal (Lipinski, 1982; Saez and Carbonnell, 1985; Lee and Catton; 1984). Another hypothesis is to consider $K r_{L}$ and $K r_{G}$ to be the relative permeabilities that can be obtained in the viscous regime where inertial forces are negligible compared to viscous forces (Turland and Moore, 1983; Lipinski, 1981; Schulenberg and Muller, 1984). The main correlations found in the literature for porous media are presented in Table 1 and plotted in Figure 1. $S_{L}$ is liquid saturation and $S_{e}$ is the effective saturation (Eq. 12) calculated with a residual saturation equal to 0.17 . To our knowledge, there is no correlation of $\eta r$ for fractures.

TABLE 1

Correlations for relative permeabilities and passabilities

\begin{tabular}{l|c|c|c|c}
\hline & $K r_{L}$ & $K r_{G}$ & $\eta r_{L}$ & $\eta r_{G}$ \\
\hline Lipinski (1980) & $S_{L}^{3}$ & $1-1.11 S_{L}$ & $S_{L}^{3}$ & $\left(1-S_{L}\right)^{3}$ \\
\hline Lipinski (1981) & $S_{L}^{3}$ & $\left(1-S_{e}\right)^{3}$ & $S_{e}^{5}$ & $\left(1-S_{e}\right)^{5}$ \\
\hline Lipinski (1982) & $S_{L}^{3}$ & $\left(1-S_{e}\right)^{3}$ & $S_{L}^{3}$ & $\left(1-S_{e}\right)^{3}$ \\
\hline $\begin{array}{l}\text { Turland and } \\
\text { Moore (1983) }\end{array}$ & $S_{L}^{3}$ & $1-S_{L}$ & $S_{e}^{4}$ & $\left(1-S_{L}\right)^{2}$ \\
\hline $\begin{array}{l}\text { Schulenberg } \\
\text { and Muller (1984) }\end{array}$ & $S_{e}^{3}$ & $\left(1-S_{e}\right)^{3}$ & $S_{e}^{5}$ & $\left(1-S_{e}\right)^{6}$ for $S_{e}<0.68$ \\
\hline $\begin{array}{l}\text { Saez and } \\
\text { Carbonnell (1985) }\end{array}$ & $S_{e}^{2.13}$ & $\left(1-S_{L}\right)^{1.8}$ & $S_{e}^{2.13}$ & $\left(1-S_{L}\right)^{1.8}$ for $S_{e}>0.68$ \\
\hline
\end{tabular}




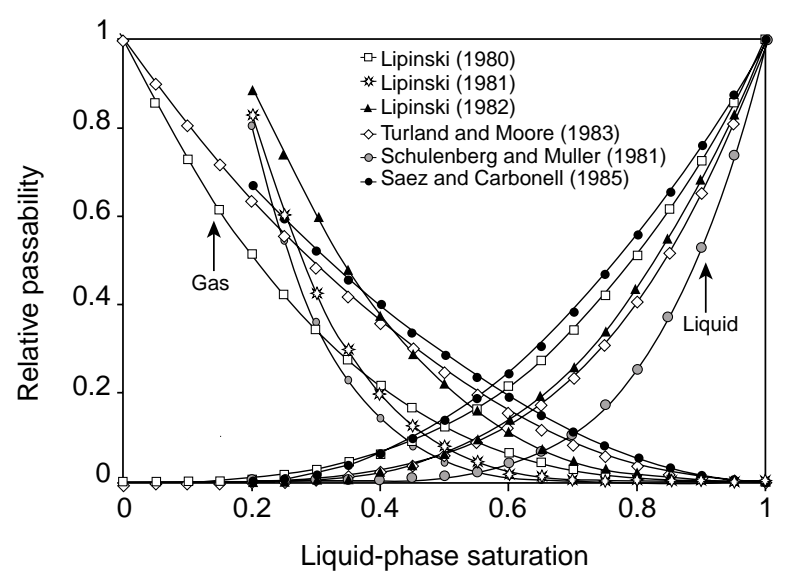

Figure 1

Correlations of relative passabilities with the liquid-phase saturation.

\subsection{The Lockhart and Martinelli Model}

This third approach does not use the terminology of relative permeability. The Lockhart and Martinelli approach was developed for two-phase flow in pipes and it is generally used in chemical engineering to analyze and design multiphase reactors (trickle bed reactors). Lockhart and Martinelli (1949) defined the following parameters:

$$
\begin{gathered}
\Phi_{L}^{2}=\frac{\mathrm{d} P / \mathrm{d} x}{\mathrm{~d} P_{L S} / \mathrm{d} x} \\
\Phi_{G}^{2}=\frac{\mathrm{d} P / \mathrm{d} x}{\mathrm{~d} P_{G S} / \mathrm{d} x} \\
\chi^{2}=\frac{\Phi_{G}^{2}}{\Phi_{L}^{2}}=\frac{\mathrm{d} P_{L S} / \mathrm{d} x}{\mathrm{~d} P_{G S} / \mathrm{d} x}
\end{gathered}
$$

where $\mathrm{d} P / \mathrm{d} x$ is the two-phase pressure gradient and $\mathrm{d} P_{L S} / \mathrm{d} x$ and $\mathrm{d} P_{G S} / \mathrm{d} x$ are the single-phase pressure gradients of liquid and gas, respectively, which would be obtained if each fluid was flowing alone at the same superficial velocity as under two-phase flow conditions. $\Phi_{L}$ and $\Phi_{G}$ are called the liquid and gas multipliers, and $\chi$ the Martinelli parameter. It may be noted that when inertial forces are negligible compared to viscous forces, Darcy's law gives the single-phase pressure gradient for each fluid and, consequently, $\chi^{2}$ and $X(E q .9)$ are equal. The various relationships between $\Phi_{L}$ (or $\Phi_{G}$ ) and $\chi$ reported in the literature are in very good agreement (Table 2 and Fig. 2). Using Figure 2, we can illustrate how simple this approach is to use. The value of $\chi$ is determined from single-phase flow experiments, say 10 , for instance. From the curve (or the table), we determine values $\Phi_{L}=1.6$ and $\Phi_{G}=16$. This means that the pressure drop during the two-phase flow is $2.6\left(=1.6^{2}\right)$ times the pressure drop when the liquid flows alone at the same velocity (or 260 times the pressure drop when the gas flows alone). The pressure drop for the single-phase flow must account for inertial effects, using the Ergun's equation or a measurement at the given flow rate.

TABLE 2

Correlations for phase multipliers

\begin{tabular}{l|ll}
\hline Sato et al. (1973) & $\Phi_{L}=1.3+1.85 \chi^{-0.85}$ & $0.1<\chi<20$ \\
\hline $\begin{array}{l}\text { Midoux, Favier } \\
\text { and Charpentier (1976) }\end{array}$ & $\Phi_{L}=1+\chi^{-1}+1.14 \chi^{-0.54}$ & $0.1<\chi<80$ \\
\hline $\begin{array}{l}\text { Rao, Ananth } \\
\text { and Varam (1983) }\end{array}$ & $\Phi_{L}=1+0.99 \chi^{-1}+1.14 \chi^{-0.5}$ & \\
\hline Tosun (1984) & $\Phi_{L}=1+\chi^{-1}+1.424 \chi^{-0.576}$ & \\
\hline
\end{tabular}

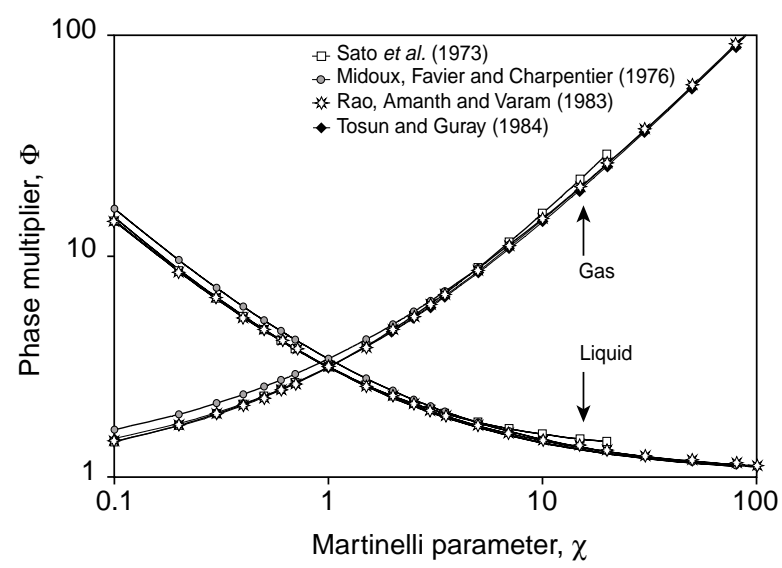

Figure 2

Correlations of phase multipliers with the Martinelli parameter.

\subsection{Discussion}

The inertial factor and the relative passability approaches are equivalent, with the obvious relationships:

$$
\beta_{L}=\frac{1}{\eta r_{L} \eta} \quad \text { and } \quad \beta_{G}=\frac{1}{\eta r_{G} \eta}
$$

However, the $\eta r$ approach is more attractive because the two terms $K r$ and $\eta r$ are more symmetrical, both increase with saturation and range between 0 and 1 .

The weak point of these two approaches is that four functions must be determined. Generally, a correlation is assumed for $K r$, and $\eta r$ (or $\beta$ ) is determined experimentally. However, the result depends highly on the correlation chosen 
for $K r$. For instance, the differences between the correlations of $\eta r$ shown in Figure 1 are mainly due to the differences between the correlations used for $K r$. One possibility is to assume that $K r$ and $\eta r$ have the same values for each phase. This assumption is equivalent to using the LockhartMartinelli approach:

$$
\Phi_{L}^{2}=\frac{1}{K r_{L}} \quad \text { and } \quad \Phi_{G}^{2}=\frac{1}{K r_{G}}
$$

On the other hand, the Lockhart-Martinelli approach has fewer adjustable parameters and it is easy to use, whether the inertial effects are negligible or not. In the first case, the single-phase pressure gradient is given by Darcy's law, and comparison between the Lockhart-Martinelli and the $\mathrm{Kr}$ approaches also leads to Equations (22).

In the following section, we will test the different models by using experimental results obtained with air and water two-phase flow in an artificial rough fracture.

\section{EXPERIMENTAL VALIDATION OF THE MODELS}

The validity of the different models is tested with the results reported in Fourar et al. (1993).

Fourar et al. (1993) have studied the air-water two-phase flow in a fracture consisting of two parallel glass plates $1 \mathrm{~m}$ long and $0.5 \mathrm{~m}$ wide. The plates were artificially roughened by gluing a single layer of 1-mm-diameter glass beads to each plate. The injector consisted of 500 stainless steel tubes with $1 \mathrm{~mm}$ outside diameter and $0.66 \mathrm{~mm}$ inside diameter. Air and water were injected through alternating capillary tubes to achieve uniform distribution of the inlet flow. For all experiments, air was injected at a constant pressure and its volumetric flow rate was measured by using a rotameter. Water was injected by a calibrated pump. At the outlet of the fracture, the gas escaped to the atmosphere and the water was collected.

The fracture was initially saturated with water, which was injected at a constant flow rate for each experiment. Air injection was then started and increased stepwise. When the steady state was reached for each flow rate, the pressure drop was recorded and liquid volume fraction (saturation) was determined from the volume of liquid displaced out of the fracture. The saturation was measured by using a balance method. Then, the fracture was re-saturated with water and the experiment was repeated several times at different liquid flow rates. Three sets of experiments were performed with rough plates. However, as the results are qualitatively similar, only one series of experiments is used for the test (aperture equal to $1.3 \mathrm{~mm}$ ).

Single-phase flow results have shown that the inertial forces were not negligible in these experiments. This observation was confirmed by the fact that the relative permeabilities calculated from the generalized Darcy's

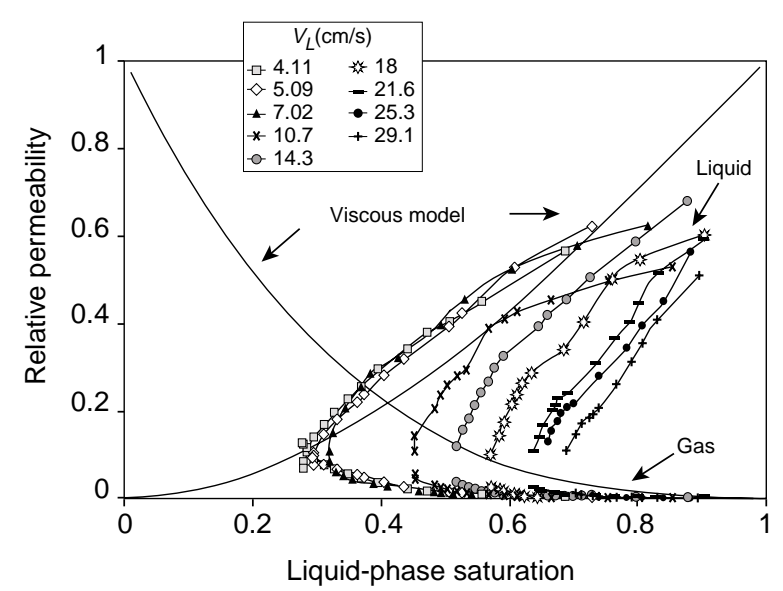

Figure 3

Relative permeabilities versus liquid-phase saturation.

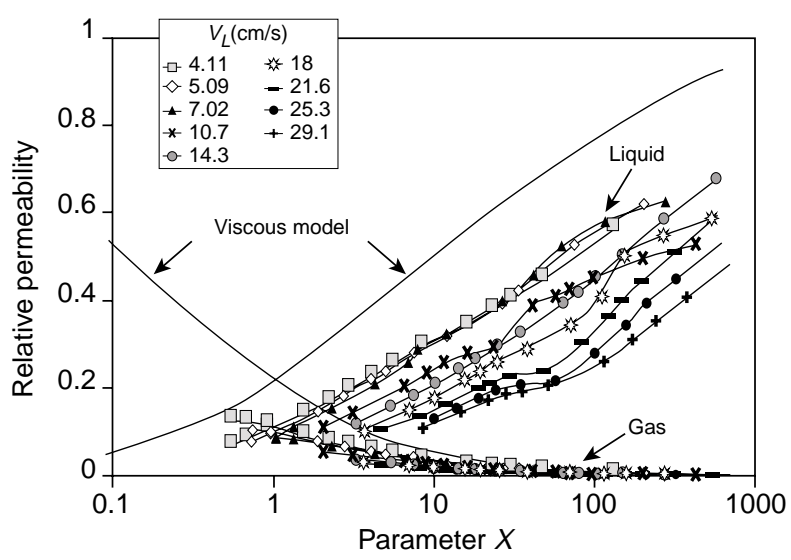

Figure 4

Relative permeabilities versus the parameter $X$.

equations (7) and (8) for various flow rates do not superpose on a single curve either as function of saturation (Fig. 3) or $X$ (Eq. 9) in Figure 4. The presence of this family of curves indicates the need for a model with an inertial contribution.

\subsection{Modeling Relative Permeability}

For fractures, Romm (1966) and Mahoney and Doggandt (1997) showed that relative permeabilities were equal to fluid saturations. However, other authors (Merrill, 1975; Kouamé, 1989; Fourar et al., 1993; Persoff and Pruess, 1995) concluded that, due to the interaction between phases, the sum of $K r$ is less than 1. To take this interaction into account, Fourar and Lenormand (1998) proposed a simple model that agrees with experiments performed without inertial effects. 
Their model takes into account the viscous coupling between the fluids and leads to the following relationships:

$$
\begin{gathered}
K r_{L}=\frac{S_{L}^{2}}{2}\left(3-S_{L}\right) \\
K r_{G}=\left(1-S_{L}\right)^{3}+\frac{3}{2} \frac{\mu_{G}}{\mu_{L}} S_{L}\left(1-S_{L}\right)\left(2-S_{L}\right)
\end{gathered}
$$

From Equations (9), (23) and (24), we can derive a relationship between the liquid-phase saturation and the flow rate ratio:

$$
X=\frac{S_{L}^{2}\left(3-S_{L}\right)}{2\left(1-S_{L}\right)^{3}+3 \frac{\mu_{G}}{\mu_{L}} S_{L}\left(1-S_{L}\right)\left(2-S_{L}\right)}
$$

This "viscous coupling" model will be used to determine the relative inertial factor and passability.

\subsection{The Inertial Factor Model}

We have seen that the inertial factor approach leads to Equations (13) and (14) containing four unknown variables: $K r_{L}, K r_{G}, \beta_{L}$ and $\beta_{G}$. For a given flow rate, the $K r_{L}$ and $K r_{G}$ are calculated using the "viscous coupling" model (Eqs. 23 and 24). Finally, $\beta_{L}$ and $\beta_{G}$ are calculated from their definition (Eq. 13 and 14). They verify:

$$
\frac{\beta_{G}}{\beta_{L}}=\frac{\rho_{L} V_{L}^{2}}{\rho_{G} V_{G}^{2}}
$$

The plot of $\beta_{L}$ and $\beta_{G}$ against the measured liquid-phase saturation is presented in Figure 5. It can be seen that there are several curves of $\beta_{L}$ and $\beta_{G}$ against $S_{L}$. However, when these factors are plotted against the parameter $X$ in Figure 6, it appears that they are a function of only the parameter $X$. Thus, relationships between $\beta_{L}$ and $\beta_{G}$ and $X$ can be obtained by the least squares method as a power law:

$$
\begin{aligned}
& \beta_{L}=572 X^{-0.51} \\
& \beta_{G}=159 X^{1.49}
\end{aligned}
$$

The measured and the calculated pressure gradients using these power laws are compared in Figure 7. In this case, the mean relative error is $9 \%$.

\subsection{The Relative Passability Model}

For this approach, it is also assumed that the relative permeabilities are given by the viscous model. The relative passabilities are then calculated from their definitions (Eqs. 16 and 17). They verify the following relationship:

$$
\frac{\eta r_{L}}{\eta r_{G}}=\frac{\beta_{G}}{\beta_{L}}=\frac{\rho_{L} V_{L}^{2}}{\rho_{G} V_{G}^{2}}
$$

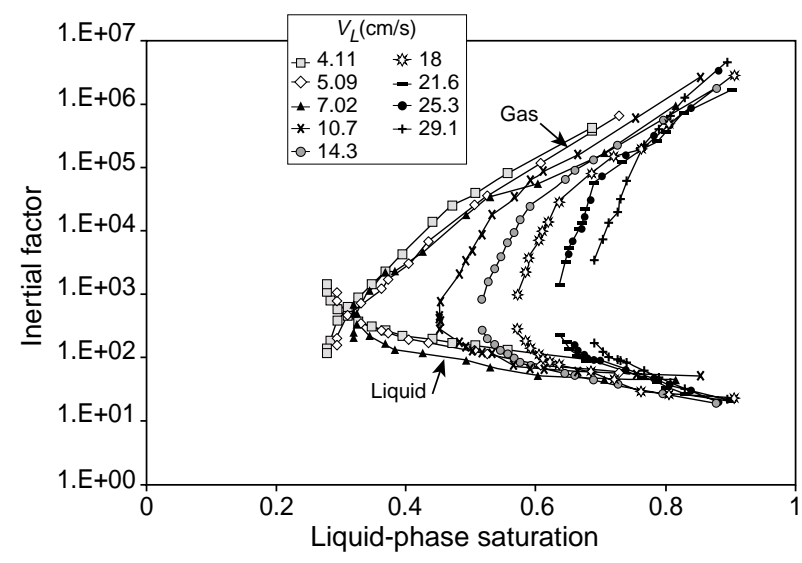

Figure 5

Inertial factors versus liquid-phase saturation.

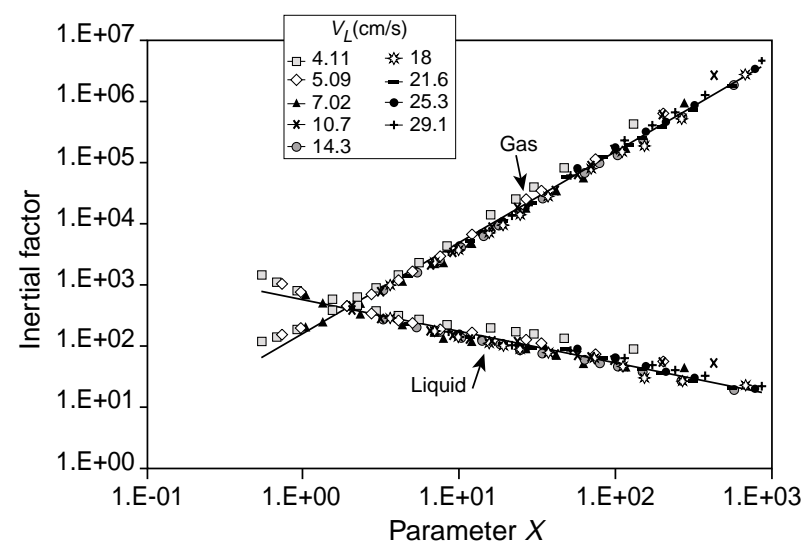

Figure 6

Inertial factors versus the parameter $X$.

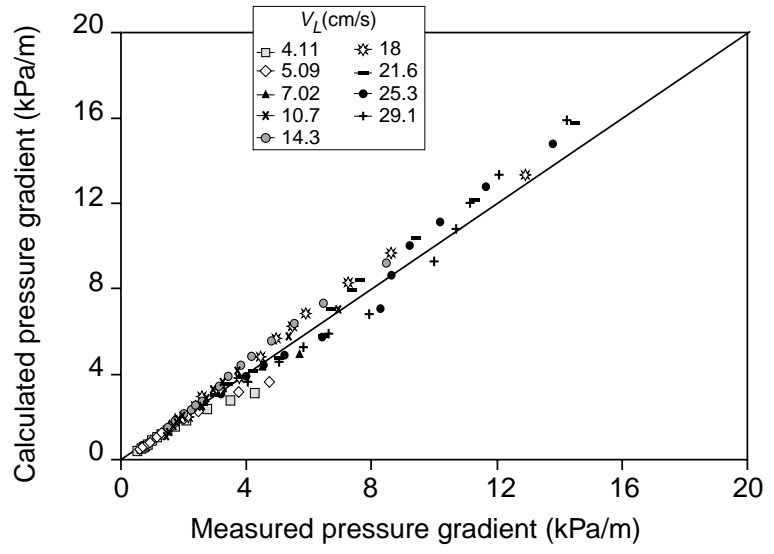

Figure 7

Comparison between measured and calculated pressure gradients using the inertial factor approach. 
which can be expressed as a function of the parameter $X$ as follows:

$$
\frac{\eta r_{L}}{\eta r_{G}}=\xi X^{2}
$$

where $\xi$ is a parameter depending on fluid properties:

$$
\xi=\frac{\rho_{L} \mu_{G}^{2}}{\rho_{G} \mu_{L}^{2}}
$$

For air and water, $\xi$ is equal to 0.278 .

Relative passabilities are first presented as a function of the measured $S_{L}$ in Figure 8 and the parameter $X$ in Figure 9. As for $\beta$, experimental results show that $\eta r_{L}$ and $\eta r_{G}$ are not only a function of the saturation. However, there is a unique curve of $\eta r$ for each fluid against the parameter $X$. This curve can be fitted by an empirical formula, which can be used in numerical simulations. Considering that $\eta r_{L}$ must be 0 when $X=0$ and that $\eta r_{G}$ equals 1 when $X$ tends to infinity, and using the relationship between $\eta r_{G}$ and $\eta r_{L}$ (Eq. 29), we propose the following expressions:

$$
\begin{aligned}
\eta r_{G} & =\frac{1}{1+\xi X^{2}+f(X)} \\
\eta r_{L} & =\frac{\xi X^{2}}{1+\xi X^{2}+f(X)}
\end{aligned}
$$

where $f(X)$ is a function of $X$ alone. Figure 10 shows that $f(X)$ can be approximated by a power law:

$$
f(X)=11.58 X^{1.53}
$$

Using the above equations, we are able to calculate the pressure gradient for a given value of the flow rate ratio. Thus, the calculated and the measured values of pressure gradient are compared in Figure 11. In this case, the mean relative error is only $7 \%$.

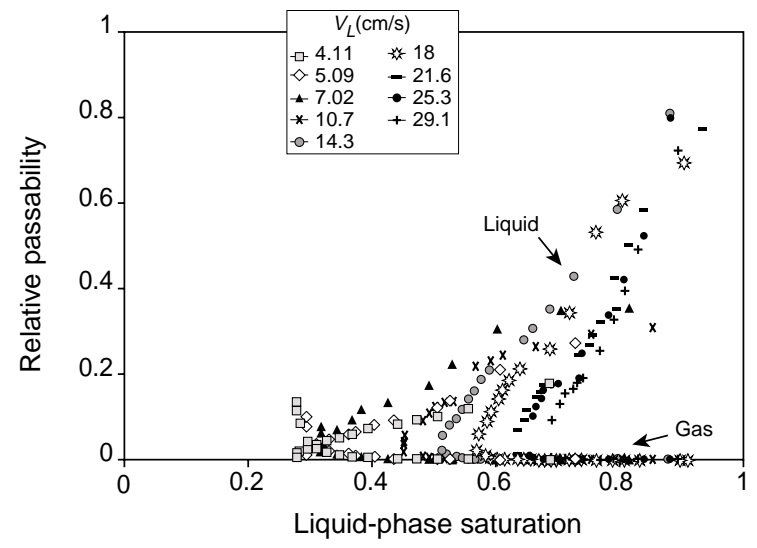

Figure 8

Relative passabilities versus liquid-phase saturation.

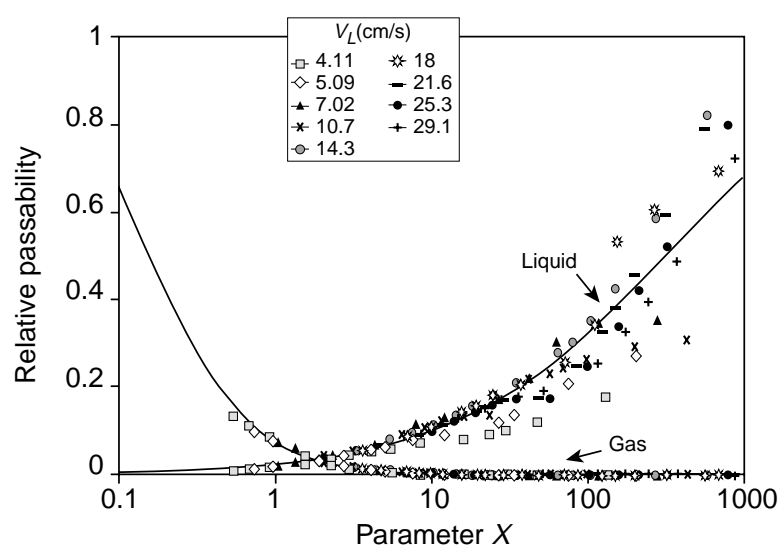

Figure 9

Relative passabilities versus the parameter $X$.

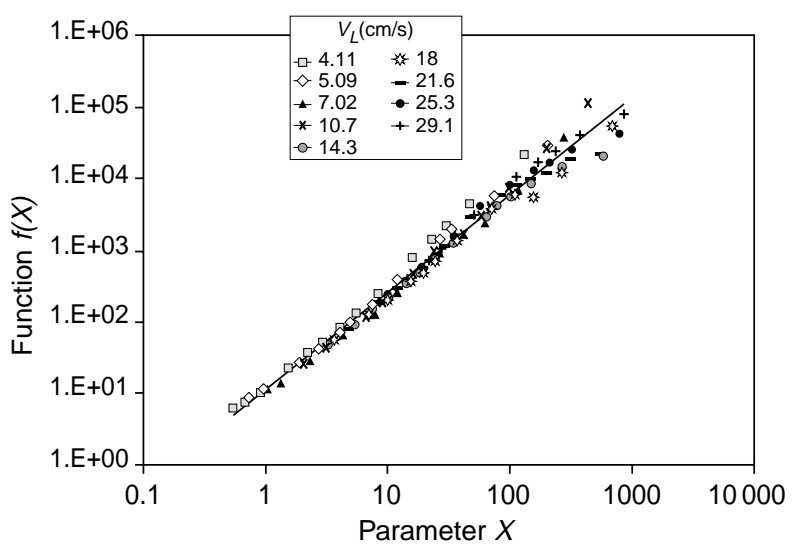

Figure 10

Function $f(X)$ defined by Equation (32) against the parameter $X$.

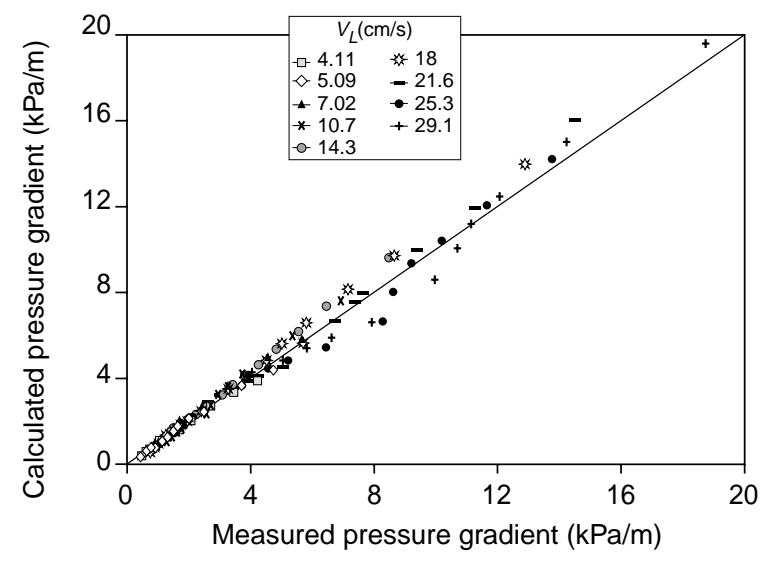

Figure 11

Comparison between measured and calculated pressure gradients using the relative passability approach. 


\subsection{The Lockhart-Martinelli Approach}

The phase multipliers $\Phi_{L}$ and $\Phi_{G}$ are first plotted as a function of saturation $S_{L}$ in Figure 12. Several curves are obtained showing that the saturation is not the judicious parameter to correlate the phase multipliers. The plot of $\Phi_{L}$ and $\Phi_{G}$ against $\chi$ (calculated using the single-phase experiments) is presented in Figure 13. The correlation of Midoux, Favier and Charpentier (1976), which was obtained for porous media (Table 2), is in good agreement with experimental fracture results. This correlation was then used to calculate pressure gradients, which were compared with the measured values in Figure 14. For low values of the pressure gradient, $\left(\mathrm{dP} / \mathrm{d} x<4 \mathrm{kPa} \cdot \mathrm{m}^{-1}\right)$ the correlation of Midoux, Favier and Charpentier (1976) is in accordance with experimental results. However, when the pressure gradient increases, the calculated values are underestimated. The mean relative error is $17 \%$.

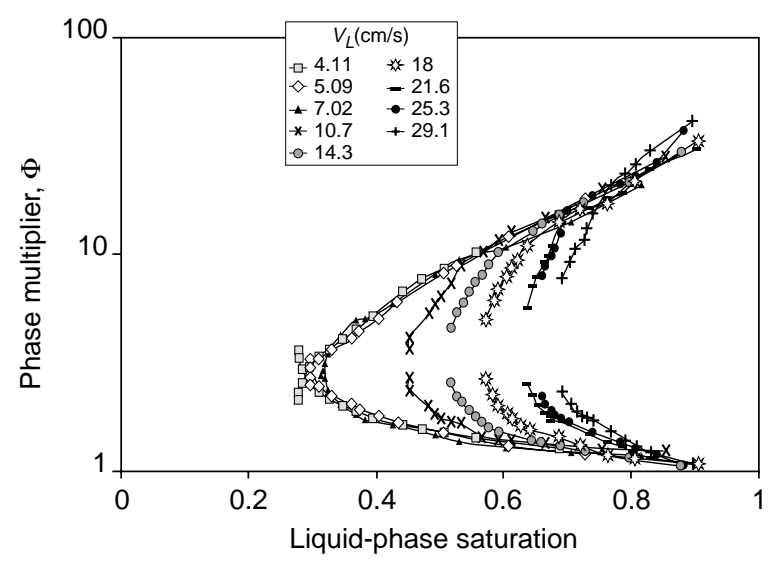

Figure 12

Phase multipliers versus liquid-phase saturation.

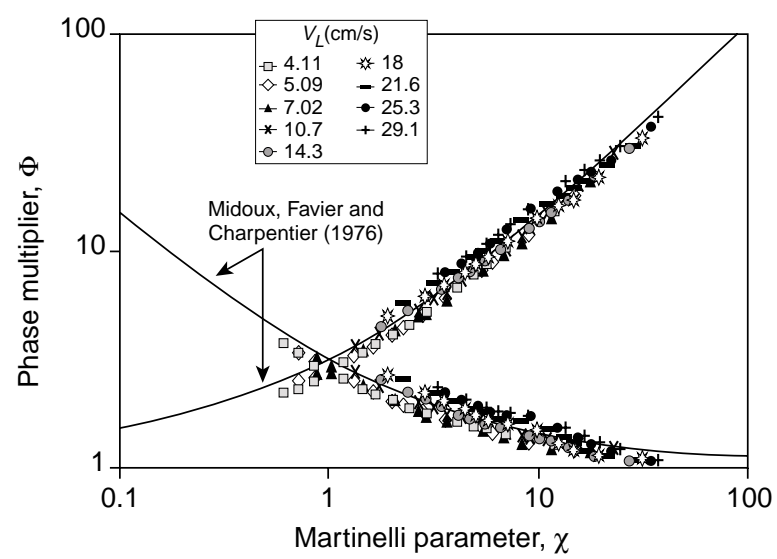

Figure 13

Phase multipliers versus the Martinelli parameter.

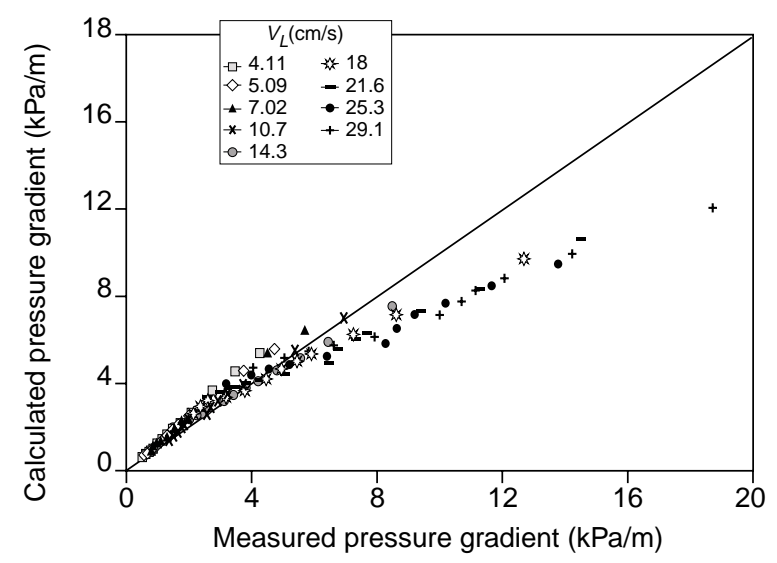

Figure 14

Comparison between measured and calculated pressure gradients using the Lockhart and Martinelli approach.

\section{CONCLUSION}

We have reviewed three different approaches used to account for inertial effects in two-phase flow through fractures: inertial factor, passability and Lockhart-Martinelli models. Using experimental results obtained with air and water in an artificial rough fracture, we compared these approaches. The main results are the following:

- the standard relative permeabilities (no inertial terms) are not only functions of the saturation but also of the flow rate ratio. This presence of a family of curves at high flow rate can be seen as a criterion for the presence of inertial effects;

- the inertial factor and passability models proposed to account for inertial effects are similar and provide a good fit of the experimental data. However, four functions must be experimentally determined. Consequently, these models cannot be used for predictions without further research;

- the relative passability model has the advantage of being dimensionless and of varying between 0 and 1 like the relative permeability;

- the Lockhart-Martinelli approach which has the advantage of using only two fitting parameters is more useful for prediction. An empirical law used in chemical engineering agrees within $20 \%$ with gas/liquid experiments without any additional adjustment of parameters;

- for the three approaches, the use of the ratio of the flow rates as a parameter gives better results than saturation.

\section{ACKN O W LEDG EMEN TS}

The authors thank C. Moyne, G. Chauveteau and J.M. Lombard for useful discussion. 


\section{REFEREN CES}

Ali, U.K., McGauley, P.J. and Wilson, C.J. (1997) The Effects of High-Velocity Flow and PVT Changes near the Wellbore on Condensate Well Performance. SPE 38923, 823-838.

Bear, J. (1972) Dynamics of Fluids in Porous Media. American Elsevier Publishing Company Inc.

Bird, R.B., Stewart, W.E. and Lightfoot, E.N. (1960) Transport Phenomena, J. Wiley \& Sons Inc.

Blom, S.M.P. and Hagoort, J. (1998) The Combined Effect of Near-Critical Relative Permeability and Non-Darcy Flow on Well Impairment by Condensate Drop-out. SPE 39976, 1-12.

Brooks, R.H. and Corey, A.T. (1966) Properties of Porous Media Affecting Fluid Flow. J. Irrig. Drainage Division, Proc. Amer. Soc. Civil Eng., 92, 61-87.

Buchlin, J.M. and Stubos, A. (1987) Phase Change Phenomena at Liquid Saturated Self Heated Particulate Beds, in Modeling and Applications of Transport Phenomena in Porous Media, Bear, J. and Buchlin, J.M. (eds.), Kluwer Acad. Pub.

Chauveteau, G. and Thirriot, C. (1967) Régimes d'écoulement en milieu poreux et limite de la loi de Darcy. La Houille Blanche, 22, $1,1-8$.

Corey, A.T. (1954) The Interelationship between Gas and Oil Relative Permeabilities. Producer's Monthly, 19, 1, 38-41.

Cornell, D. and Katz, D.L. (1953) Flow of Gases through Consolidated Porous Media. Ind. Eng. Chem., 45, 2145-2153.

Darcy, H. (1856) Les fontaines publiques de la ville de Dijon, Dalmont.

Dullien, F.A.L. (1992) Porous Media-Fluid Transport and Pore Structure, Academic Press, Inc.

Ergun, S. (1952) Fluid Flow through Packed Columns. Chem. Eng. Progr., 48, 2, 89-94.

Evans, E.V. and Evans, R.D. (1986) The Influence of an Immobile or Mobile Saturation upon Non-Darcy Compressible Flow of Real Gases in Propped Fractures. SPE 15066, 181-195.

Evans, R.D., Hudson, C.S. and Greenlee, J.E. (1987) The Effect of an Immobile Liquid Saturation on the Non-Darcy Flow Coefficient in Porous Media, SPE Production Engineering, 331-338.

Forchheimer, P. (1914) Chap. 15, in Hydraulik, Teubner.

Fourar, M., Bories, S., Lenormand, R. and Persoff, P. (1993) Two-Phase Flow in Smooth and Rough Fractures: Measurement and Correlation by Porous-Media and Pipe-Flow Models. Water Resources Research, 29, 11, 3699-3708.

Fourar, M. and Lenormand, R. (1998) A Viscous Coupling Model for Relative Permeabilities in Fractures. SPE 49006, 253-258.

Geertsma, J. (1974) Estimating the Coefficient of Inertial Resistance Fluid Flow through Porous Media. SPE 4706, 445450.

Hubbert, M.K. (1956) Darcy Law and the Field Equations of the Flow of Underground Fluids. Trans. Amer. Inst. Min. Mandal. Eng., 207, 222-239.

Kouamé, S. (1989) Étude expérimentale d'écoulements diphasiques en fracture. Ph.D. Thesis, Inst. Nat. Poly. Toulouse.

Lee, H.S. and Catton, I. (1984) Two-Phase Flow in Stratified Porous Media. 6th Information Exchange Meanding on Debris Coolability, Los Angeles.
Lindquist, E. (1933) On the Flow of Water through Porous Soil. Premier Congrès des grands barrages, Stockholm, 5, 81-101.

Lipinski, R.J. (1980) A Particle Bed Dryout Model with Upward and Downward Boiling. Trans. Am. Nucl. Soc., 35, 350-358.

Lipinski, R.J. (1981) A One-Dimensional Particle Bed Dryout Model. Trans. Am. Nucl. Soc., 38, 386-387.

Lipinski, R.J. (1982) A Model for Boiling and Dryout in Particle Beds. Report SAND 82-0756 (NUREG/CR-2646), Sandia Labs.

Lockhart, R.W. and Martinelli, R.C. (1949) Proposed Correlation of Data for Isothermal Two-Phase, Two-Component Flow in Pipes. Chem. Eng. Progr., 45, 39-48.

Mahoney, D. and Doggandt, K. (1997) Multiphase Flow in Fractures. Proc. of the Meanding of the Sociandy of Core Analysts, Calgary, Canada.

Marle, C.M. (1981) Multiphase Flow in Porous Media, Gulf Publishing Co.

Martins, J.P., Milton-Taylor, D. and Leung, H.K. (1990) The Effects of Non-Darcy Flow in Propped Hydraulic Fractures. SPE 20709, 899-913.

Merrill, L.S. (1975) Two-Phase Flow in Fractures. Ph.D. Thesis, University of Denver.

Midoux, N., Favier, M. and Charpentier, J.C. (1976) Flow Pattern, Pressure Loss and Liquid Holdup Data in Gas-Liquid Downflow Packed Beds with Foaming and Nonfoaming Hydrocarbons. J. Chem. Eng. Japan, 9, 5, 350-356.

Narayanaswamy, G., Sharma, M.M. and Pope, G.A. (1998) Effect of Heterogeneity on the Non-Darcy Flow Coefficient. SPE 39979, 215-226.

Neasham, J.W. (1977) The Morphology of Dispersed Clay in Sandstone Reservoirs and its Effects on Sandstone Shaliness, Pore Space and Fluid Flow Properties. 52nd Anual Fall Meanding of the SPE, Colorado, Oct. 9-12, SPE 6858.

Noman, R. and Archer, J.S. (1987) The Effect of Pore Structure on Non-Darcy Gas Flow in some Low Permeability Reservoir Rocks. SPE 16400, 103-110.

Persoff, P. and Pruess, K. (1995) Two-Phase Flow Visualization and Relative Permeability Measurement in Natural RoughWalled Rock Fractures. Water Resources Research, 31, 5, 11751186 .

Rao, V.G., Ananth, M.S. and Varam, Y.B.G. (1983) Hydrodynamics of Two-Phase Co-Current Downflow through Packed Beds. AIChE Journal, 29, 467-483.

Romm, E. S. (1966) Fluid Flow in Fractured Rocks (in Russian), Nedra Publishing House, Moscow (English translation: Blake, W.R., Bartlesville, OK, 1972).

Saez, A.E. and Carbonnell, R.G. (1985) Hydrodynamic Parameters for Gas-Liquid Co-Current Flow in Packed Beds. AIChE Journal, 31, 52-62.

Sato, Y., Hirose, T., Takahashi, F. and Toda, M. (1973) Pressure Loss and Liquid Holdup in Packed Bed Reactor with Cocurrent Gas-Liquid Downflow. J. Chem. Eng. Japan, 6, 147.

Scheidegger, A.E. (1960) The Physics of Flow through Porous Media, University of Toronto Press.

Schneebeli, G. (1955) Expériences sur la limite de validité de la loi de Darcy et l'apparition de la turbulence dans un écoulement de filtration. La Houille Blanche, 10, 2, 141-149.

Schulenberg, T. and Muller, U. (1984) A Refined Model for the Coolability of Core Debris with Flow Entry from the Bottom. 6th 
Information Exchange Meanding on Debris Coolability, Los Angeles.

Tiss, M. and Evans, R.D. (1989) Measurement and Correlation of Non-Darcy Flow Coefficient in Consolidated Porous Media. J. Pand. Sci. Eng., 3, 19-33.

Tosun, G. (1984) A Study of Cocurrent Downflow of Nonfoaming Gas-Liquid System in Packed Bed. 1. Flow Regimes: Search for a
Generalized Flow Map. 2. Pressure Drop: Search for a Correlation. Ind. Eng. Chem. Process Des. Dev., 23, 1, 9-35.

Turland, B.D. and Moore, K.A. (1983) One-Dimensional Models of Boiling and Dryout. Post Accident Debris Colling. Proc. 5th Post Accident Heat Removal Information Exchange Mtg., Karlsruhe, July 1982.

Final manuscript received in December 1999 